\title{
The Implications of Power Mobility on Body Weight in a Veteran Population
}

\author{
Deborah Caruso, MD; Rajbir S. Chaggar, MD; Scott D. McDonald, PhD; Christo X. Arbonies, MD; and David X. Cifu, MD
}

Background: The prevalence of obesity is increasing in the United States. A common concern among health care providers is that prescribing a power mobility device (PMD) may decrease physical activity and lead to obesity and increasing morbidity. This study analyzes the effect of PMD prescriptions over a 2-year period on body mass index (BMI) and body weight in a population of veterans both as a whole and in BMI/age subgroups.

Methods: Prosthetics department medical records of veterans who received PMDs for the first time between January 1, 2011 and June 30, 2012 were reviewed. Of 399 records reviewed, 185 veterans met criteria for data analysis. The primary outcome measure was the change in $\mathrm{BMI}$ and body weight from time 1 (date of PMD prescription) to time 2 (2 years later).

Results: There was a significant decrease in BMI and weight in the first 2 years after receiving a PMD prescription. However, age moderated the relationship between BMI and time.

Conclusions: PMD use does not seem to be associated with significant weight change. Further studies using control groups and assessing comorbidities are needed.
Author affiliations can be found at the end of the article.

Correspondence:

Deborah Caruso

(deborah.caruso2@va.gov)

Fed Pract. 2021;38(9).

Published online September 12. doi:10.12788/fp.0171
T he Veterans Health Administration (VHA) clinical practice recommendations endorse a power mobility device (PMD) for individuals with adequate judgment, cognitive ability, and vision who are unable to propel a manual wheelchair or walk community distances despite standard medical and rehabilitative interventions. ${ }^{1}$ VHA supports the use of a PMD in order to access medical care and accomplish activities of daily living, both at home and in the community for veterans with mobility limitations secondary to cardiovascular disease, neurologic disorders, pulmonary disease, or musculoskeletal disorders. The goal of a PMD use is increased participation in community and social life, improved health maintenance via enhanced access to medical facilities, and an overall enhanced quality of life. However, there is a common concern among health care providers that prescribing a PMD may decrease physical activity, in turn, leading to obesity and increasing morbidity. ${ }^{2}$

The prevalence of obesity is increasing in the United States. In the past decade 35.0\% of men and $36.8 \%$ of women were classified as obese (body mass index [BMI], $\geq 30$ ). ${ }^{3}$ Recent figures from the Centers for Disease Control and Prevention estimate that the overall prevalence of obesity in Americans is closer to $42.4 \%$. ${ }^{4}$ The veteran population is not immune to this; a 2014 study of nearly 5 million veterans reported that the prevalence of obesity in this population was $41 \% .^{5,6}$ In addition to obesity being im- plicated in exacerbating many medical problems, such as osteoarthritis, insulin resistance, and heart disease, obesity also is associated with a significant decrease in lifespan. ${ }^{7}$ Almost half of adults who report ambulatory dysfunction are obese. ${ }^{8}$ Given the increased morbidity and mortality as a result of obesity, interventions that may promote weight gain need to be appropriately identified and minimized.

In a retrospective study of 89 veterans, Yang and colleagues demonstrated no significant weight change 1 year after initial PMD prescription. ${ }^{2}$ Another study of 102 patients noted no significant weight changes 1 year after PMD prescription. ${ }^{9}$ This study analyzes the effect of PMD prescriptions over a 2-year period on BMI and body weight in a larger population of veterans both as a whole and in BMI/age subgroups.

\section{METHODS}

The institutional review board at Hunter Holmes McGuire Veterans Affairs Medical Center in Richmond, Virginia, reviewed and approved this study. A waiver of participant consent was approved due to the nature of the research (medical records of patients, some of whom were deceased) and the type of data collected (retrospective data). In addition, each individual was assigned a sequential code to de-identify any personal information. Prosthetics department medical records of consecutive veterans who received PMDs for the first time between January 1, 2011 and June 30, 2012, were reviewed. 
FIGURE 1 Inclusion Criteria Algorithm

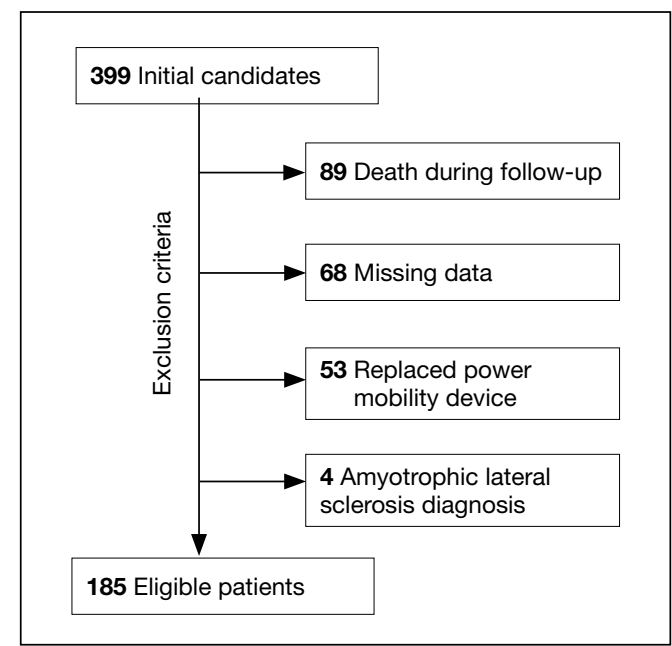

Data extracted from the electronic health record (EHR) included demographics, indication for power mobility, weight at time of PMD prescription, weight at 2-years postprescription, and height. Weight readings were considered valid if weight was taken within 3 months of initial prescription and then again within 3 months at the 2-year interval. Individuals without weights recorded in these time frames were excluded. In addition, we excluded medical conditions that might significantly affect body weight, including amyotrophic lateral sclerosis (ALS), amputation during the study period, or history of weight loss surgery. Cancer diagnoses were excluded as they were not an indication for power mobility in the VHA. ALS, though variable in its disease course, was specifically excluded given the likelihood of these patients dying of the natural progression of the disease before the 2-year follow-up period: Median survival times in patients diagnosed with ALS aged $>60$ years was $<15$ months. ${ }^{10-12}$

The EHRs of 399 individuals who received a PMD during the period were reviewed, and 185 veterans met criteria for data analysis. Subject exclusions in the weight and BMI analysis included death during the follow-up period (89), missing data (68), prior PMD users who came in for replacements (53), and ALS (4) (Figure 1). Patients were not excluded based on the presence or absence of intentional weight loss efforts as this information was not readily available through chart review.
TABLE 1 Baseline Patient Demographics $(\mathrm{N}=185)$

\begin{tabular}{lc} 
Characteristics & Results \\
\hline Female, No. (\%) & $4(2.2)$ \\
\hline Male, No. (\%) & $181(97.8)$ \\
\hline Race, No. (\%) & \\
White & $117(63.2)$ \\
Black & $63(34.1)$ \\
Other & $5(2.7)$ \\
\hline Device indications, No. (\%) & \\
Musculoskeletal disorders & $77(41.6)$ \\
Pulmonary disorders & $47(25.4)$ \\
Cardiovascular disorders & $44(23.8)$ \\
Other & $17(9.2)$ \\
\hline Age (range), y & $67.3(26-90)$ \\
$<65$ y, No. (\%) & $84(45.4)$ \\
$\geq 65$ y, No. (\%) & $101(54.6)$ \\
\hline Body mass index, mean (range) & $31.5(14.2-63.4)$ \\
\hline Weight, mean (range), lb & $219.0(110-479)$
\end{tabular}

\section{Statistical Analysis}

The primary outcome measure was the change in BMI and body weight from time 1 (date of PMD prescription) to time 2 (2 years later). Analyses were performed using IBM SPSS Statistics, Version 21. BMI was calculated using the weight (lb) x 703/ (height [inches]). ${ }^{2}$ Dichotomization of BMI was performed using the conventional cut scores: < 30.0, not obese; and $\geq 30.0$, obese. Paired $t$ tests and SPSS general linear model (repeated measures) were used to examine change of BMI from time 1 to time 2. The exact McNemar test was used to examine change in obesity classification across time 1 and time 2. Correlating with Yang's retrospective observational study, data were analyzed separately for aged $<65$ years and aged $\geq 65$ years. $^{2}$

\section{RESULTS}

Of the 185 veterans, 181 were male (98\%); mean age was 67.3 years (range, 26-90); and $55 \%$ were aged $\geq 65$ years. Musculoskeletal disorders (41.6\%) were the most common primary indication for a PMD, followed by pulmonary disorders (25.4\%) and cardiovascular disorders (23.8\%) (Table 1 ).

There was a significant decrease in BMI in the first 2 years after receiving a PMD prescription for the first time 
TABLE 2 Obesity Rate Comparison

\begin{tabular}{llll} 
Groups & Time 1 & Time 2 & Analysis \\
\hline Patients, No. & 185 & 185 & \\
BMl, mean (SD) [range] & $31.5(8.3)[14.3-63.4]$ & $30.9(8.4)[14.6-70.2]$ & $P=.02 ; F=5.57 ; P$ Partial $\eta^{2}=.03$ \\
Weight, mean (SD) [range], lb & $\begin{array}{l}219.0(62.6)[110-479] \\
\text { Obese (BMI } \geq 30), \%\end{array}$ & $\begin{array}{l}215.3(63.4)[91-461] \\
46.5\end{array}$ & $\begin{array}{l}P=.03 ; F=4.90 ; \text { partial } \eta^{2}=.03 \\
\text { Exact McNemar test, } P=.26\end{array}$ \\
\hline Aged $<65$ y, No. & 49.7 & 84 & \\
BMl, mean & 84 & 33.1 & $P=.45 ; F=0.58 ;$ partial $\eta^{2}=.003$ \\
Weight, mean, lb & 32.9 & 232.6 & $P=.36 ; F=0.85 ;$ partial $\eta^{2}=.005$ \\
Obese (BMI $\geq 30), \%$ & 230.6 & 56.0 & Exact McNemar test, $P=.69$ \\
\hline Aged $\geq 65$ y, No. & 53.6 & 101 & $P<.001 ; F=18.81 ;$ partial $\eta^{2}=.09$ \\
BMl, mean & 101 & 29.1 & $P<.001 ; F=18.47 ;$ partial $\eta^{2}=.09$ \\
Weight, mean, lb & 30.3 & 200.9 & Exact McNemar test, $P=.06$
\end{tabular}

Abbreviation: BMI, body mass index.

(estimated marginal means: 31.5 to 30.9 , $P=.02)$. However, age moderated the relationship between BMI and time $F[1,183]=$ $12.14, P=.001$, partial $\eta^{2}=.06$ (Table 2). The 101 subjects aged $>65$ years experienced a significant decrease in BMI (estimated marginal means: 30.3 to $29.1, P<.001$ ), whereas the 84 patients aged $<65$ years experienced a slight and nonsignificant increase in BMI (estimated marginal means: 32.9 to 33.1, $P$ $=.45)$. BMI was significantly higher for subjects aged $<65$ years at Time $1(F[1,183]=$ 4.32, $P=.04$, partial $\left.\eta^{2}=.02\right)$ and at Time 2 $\left(F[1,183]=11.04, P=.001\right.$, partial $\left.\eta^{2}=.06\right)$.

Similarly, there was a significant decrease in weight in the first year after receiving a PMD prescription with a change in mean weight from 219.0 to $215.3 \mathrm{lb}$ $(P=.3)$. Again, age moderated the relationship between weight and time $(F=12.81$; $P<.001$; partial $\left.\eta^{2}=.07\right)$. Individuals aged $\geq 65$ years experienced a significant decrease in weight (estimated marginal means $=209.4$ to 200.9; $P<.001)$, whereas those aged $<65$ years experienced a slight and nonsignificant increase in weight (230.6 to 232.6; $P=.36$ ). Weight was significantly higher for individuals aged $<65$ years at time $1\left(F=5.34 ; P=.02 ;\right.$ partial $\left.\eta^{2}=.03\right)$ and at time $2(F=12.18 ; P=.001 ;$ partial $\left.\eta^{2}=.06\right)$.

The percentage of those who were obese (BMI $\geq 30)$ at time $1(49.7 \%)$ did not significantly change at time 2 (46.5\%) (exact McNemar test, $P=.26)$. Similarly, there was no significant change in obesity from time 1 to time 2 for those aged $<65$ years (exact
McNemar test $P=.69$ ) or for those aged $\geq 65$ years (exact McNemar test $P=.06$ ) (Figure 2). Obesity at time 2 was significantly more common in those aged $<65$ years $(56.0 \%)$ than those aged $\geq 65$ years $(38.6 \%)$, $\chi^{2}[1]=5.54 ; P=.02$. Obesity at time $1 \mathrm{did}$ not differ between those aged $<65$ years $(53.6 \%)$ and aged $\geq 65$ years $(46.5 \%)$, $\eta^{2}[1]=0.9 ; P=.34$. Obesity moderated the relationship between weight and time $\left(F=5.10 ; P=.03\right.$; partial $\left.\eta^{2}=.03\right)$ in that obese individuals experienced a significant decrease in weight with estimated marginal means $(S E)=264.5(4.51)$ to 257.4 (4.97); $F=11.32 ; P<.001$; partial $\left.\eta^{2}=.06\right)$, whereas nonobese individuals had no weight change with estimated marginal means $(\mathrm{SE})=174.0(4.48)$ to 173.61 (4.94); $F=.03 ; P<.86 ;$ partial $\left.\eta^{2}<.01\right)$.

\section{DISCUSSION}

This study demonstrated a significant decrease in both weight and BMI at 2 years after the initiation of a PMD in patients aged $<65$ years. No significant change was found for obesity rates. However, veterans who met criteria for obesity at the time of PMD prescription saw a significant decrease in their weight at 2 years compared with those who were nonobese.

VHA supports power mobility when there is a clear functional need that cannot be met by rehabilitation, surgical, or medical interventions to enhance veterans' abilities to access medical care, accomplish necessary tasks of daily living, and to have greater access to their com- 
munities. Though limited by strength of association, studies involving PMD users generally found improvement in reported functional outcomes and overall satisfaction with PMD use based on a systematic review. ${ }^{13}$ Nonetheless, there is an implicit concern among providers that a PMD prescription, by limiting physical activity, may exacerbate obesity trends in potentially high-risk individuals.

However, a controversy exists about whether increasing physical activity alone leads to weight loss. A 2007 study followed 102 sedentary men and 100 women over 1 year randomized to moderately intensive exercise for 60 minutes, 6 days a week vs no intervention. ${ }^{14}$ The men lost an average of 4 pounds, and women lost an average of 3 pounds after 1 year. The Women's Health Study divided 39,876 women into high, medium, and low levels of exercise groups. After 10 years, the intense exercise group did not have any significant weight loss. ${ }^{15}$

Our study was consistent with existing literature in that a PMD prescription did not correlate with weight gain. ${ }^{2,9}$ In our veteran population aged $\geq 65$ years, we observed an opposite trend of weight loss after PMD prescription. Of note, studies have shown that peak body weight occurs in the sixth decade, remains stable until about aged 70 years, and then slowly decreases thereafter, at a rate of 0.1 to $0.2 \mathrm{~kg}$ per year. ${ }^{16}$ This likely explains some of the weight loss trend we observed in our study of veterans aged $\geq 65$ years. Possible additional explanations include improved access to health care and to more nutritional foods that promote general health and well-being.

\section{Limitations}

The data were gathered from a predominantly male veteran population, potentially limiting generalizability. The health of any individual is determined by the interaction of factors of which body weight is just a single, isolated component. As such, the effect of powered mobility on body weight is not a direct reflection on the effect on overall health. Additionally, there are many factors that may affect an individual's body weight, such as optimal management of medical comorbidities, which could not
FIGURE 2 Change in Body Mass Index After Prescription

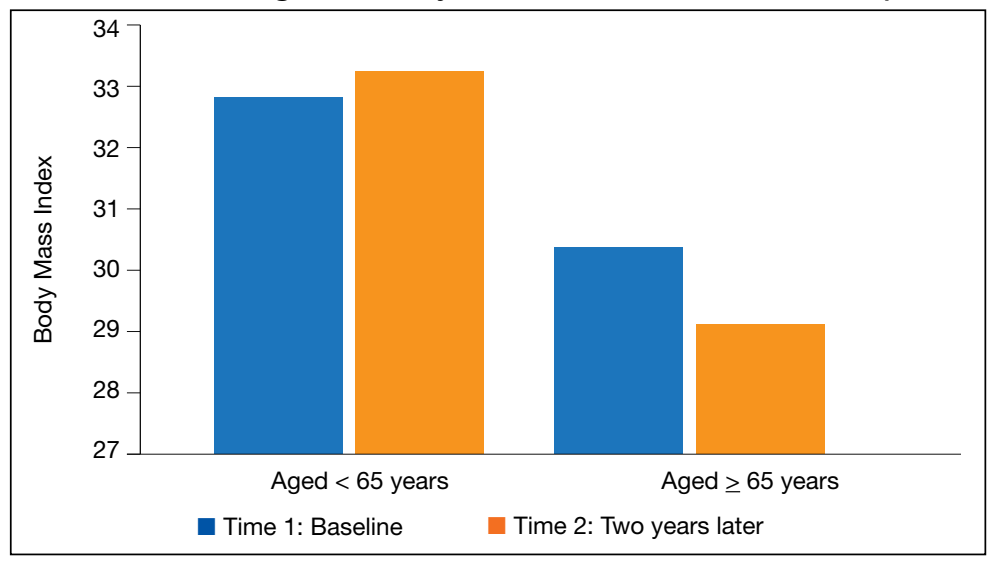

be controlled for in this study. Also, while these values can be compared with other veteran populations, this study had no true control group.

\section{CONCLUSIONS}

Based on the findings of this study with aforementioned limitations, PMD use does not seem to be associated with significant weight changes. Further studies using control groups and assessing comorbidities are needed.

\section{Author affiliations}

Deborah Caruso is a Physical Medicine and Rehabilitation Staff Physician, and Scott McDonald is a Clinical Psychologist, both at Hunter Holmes McGuire Veterans Affairs Medical Center in Richmond, Virginia. David Cifu is a Senior Traumatic Brain Injury Specialist for the US Department of Veterans Affairs. Christo Arbonies is a Physical Medicine and Rehabilitation Staff Physician at Ochsner Medical Center in New Orleans, Louisiana. Rajbir Chaggar is a Physical Medicine and Rehabilitation Resident Physician, and David Cifu is Associate Dean of Innovation and Systems Integration, both at Virginia Commonwealth University Health System in Richmond.

\section{Author disclosures}

The authors report no actual or potential conflicts of interest with regard to this article.

\section{Disclaimer}

The opinions expressed herein are those of the authors and do not necessarily reflect those of Federal Practitioner, Frontline Medical Communications Inc., the US Government, or any of its agencies.

\section{References}

1. Perlin J. Clinical practice recommendations for motorized wheeled mobility devices: scooters, pushrim-activated power-assist wheelchairs, power wheelchairs, and power wheelchairs with enhanced function. Published 2004. Accessed August 12, 2021. https://www.prosthetics.va.gov /Docs/Motorized_Wheeled_Mobility_Devices.pdf

2. Yang W, Wilson L, Oda I, Yan J. The effect of providing 
power mobility on weight change. Am J Phys Med Rehabil. 2007;86(9):746-753. doi:10.1097/PHM.0b013e31813e0645

3. Yang, L, Colditz GA. Prevalence of overweight and obesity in the United States, 2007-2012. JAMA Intern Med. 2015; 175(8):1412-1413. doi:10.1001/jamainternmed.2015.2405

4. Hales CM, Carroll MD, Fryar CD, Ogden CL. Prevalence of obesity and severe obesity among adults: United States, 2017-2018. NCHS Data Brief, no 360. Hyattsville, MD: National Center for Health Statistics; 2020.

5. Almond N, Kahwati L, Kinsinger L, Porterfield D. The prevalence of overweight and obesity among U.S. military veterans. Mil Med. 2008;173(6):544-549. doi:10.7205/milmed.173.6.544

6. Breland JY, Phibbs CS, Hoggatt KJ, et al. The obesity epidemic in the Veterans Health Administration: prevalence among key populations of women and men veterans. J Gen Intern Med. 2017;32(suppl 1):11-17. doi:10.1007/s11606-016-3962-1

7. Bray G. Medical consequences of obesity. Int Clin Endocrinol Metab. 2004;89(6):2583-2589. doi:10.1210/jc.2004-0535

8. Fox $\mathrm{MH}$, Witten $\mathrm{MH}$, Lullo $\mathrm{C}$. Reducing obesity among people with disabilities. J Disabil Policy Stud. 2014;25(3):175-185. doi:10.1177/1044207313494236

9. Zagol BW, Krasuski RA. Effect of motorized scooters on quality of life and cardiovascular risk. Am J Cardiol. 2010;105(5):672-676. doi:10.1016/j.amjcard.2009.10.049

10. Traxinger K, Kelly $C$, Johnson BA, Lyles $R H$, Glass JD. Prognosis and epidemiology of amyo- trophic lateral sclerosis: analysis of a clinic population, 1997-2011. Neurol Clin Pract. 2013;3(4):313-320. doi:10.1212/cpj.0b013e3182a1b8ab

11. Wolf J, Safer A, Wöhrle J, et al. Factors predicting oneyear mortality in amyotrophic lateral sclerosis patientsdata from a population-based registry. BMC Neurol. 2014;14(1):197. doi:10.1186/s12883-014-0197-9

12. Körner S, Hendricks M, Kollewe K, et al. Weight loss, dysphagia and supplement intake in patients with amyotrophic lateral sclerosis (ALS): impact on quality of life and therapeutic options. BMC Neurol. 2013;13:84. doi: 10.1186/1471-2377-13-84

13. Auger CJ, Demers L, Gélinas I, et al. Powered mobility for middle-aged and older adults: systematic review of outcomes and appraisal of published evidence. Am J Phys Med Rehabil. 2008;87(8):666-680. doi:10.1097/PHM.0b013e31816de163

14. McTiernan A, Sorensen B, Irwin M, et al. Exercise effect on weight and body fat in men and women. Obesity (Silver Spring). 2007;15(6):1496-512. doi:10.1038/oby.2007.178

15. Lee IM, Djoussé L, Sesso H, Wang L, Buring JE . Physical activity and weight gain prevention, women's health study. JAMA. 2010;303(12):1173-1179. doi:10.1001/jama.2010.312

16. Wallace J, Schwartz R. Epidemiology of weight loss in humans with special reference to wasting in the elderly. Int $J$ Cardiol. 2002;85(1):15-21. doi:10.1016/s0167-5273(02)00246-2 